\title{
SOLDADURAS 2000
}

\section{WELD 2000}

\section{AUTORES}

Arturo Pérez París: Alumno de la Escuela Politécnica de la Universidad de Alcalá. arturo.perez@arrakis.es

\section{CURRÍCULUM VITAE}

Alumno de la Escuela Politécnica de la Universidad de Alcalá de Henares (España). Ingeniero de Soporte Técnico en Kone Elevadores (España).

\section{RESUMEN}

Hace exactamente un año, comencé a escribir en esta magna revista. Me felicito por ello, sobre todo por el hecho de que no me hayan mandado a freír espárragos por rollista. Aunque quizás esto sea todavía posible. Como diría el gran Bogart en: El sueño eterno: ... hasta que no cante la gorda no se termina la ópera. En fin, si mal no recuerdo, fue con el artículo: Todo lo que quería saber sobre la soldadura y no se atrevía a preguntar. En él presenté un tema eminentemente poco académico, aunque sí muy práctico. No obstante, quedaron cosas por decir, y aunque segundas partes nunca fueron buenas, intentaré completar aquel; cumpliendo así la promesa que en él hice.

\section{PALABRAS CLAVE}

Soldadura - Metales - Sutura 


\section{ABSTRACT}

Exactly one year ago, I started writing in this great magazine. I welcome it, especially by the fact that I have commanded rollista fry asparagus. Although perhaps this is still possible. To quote the great Bogart: The Big Sleep: ... until the fat lady singing opera is not over. Well, if I remember correctly, was with Article: All you wanted to know about welding and dared not ask. It recently introduced a subject eminently academic, although very practical. However, things were said, and even sequels were never good, try to complete one, fulfilling the promise that he did.

\section{KEY WORDS}

Welding - Metals - Suture

Hace exactamente un año, comencé a escribir en esta "magna revista". Me felicito por ello, sobre todo por el hecho de que no me hayan mandado "a freír espárragos" por rollista. Aunque quizás esto sea todavía posible. Como diría el gran Bogart en "El sueño eterno": "...hasta que no cante la gorda no se termina la ópera". En fin, si mal no recuerdo, fue con el artículo "Todo lo que quería saber sobre la soldadura y no se atrevía a preguntar". En él presenté un tema eminentemente poco académico, aunque sí muy práctico. No obstante, quedaron cosas por decir, y aunque segundas partes nunca fueron buenas, intentaré completar aquel; cumpliendo así la promesa que en él hice. 
Parafraseando a D. Enrique Tierno Galván al volver a dar clase después del exilio y salvando las distancias:

'Como decíamos ayer', a la soldadura con metales de fácil fusión, como el plomo y el estaño, se la llama soldadura blanda. Normalmente no se emplean el estaño o plomo solos, sino una aleación de ambos en proporciones adecuadas, según el metal a soldar y el trabajo al que se dedicará la pieza soldada. Para las que haremos en electrónica será al $60 \%$ plomo y el $40 \%$ estaño. Este tipo de soldadura se emplea cuando la pieza, en su trabajo, no sobrepasa la temperatura de los $200{ }^{\circ} \mathrm{C}$.

La soldadura blanda se suele emplear en la unión de chapas y piezas de latón, hojalata, cobre o bronce, colectores de inducidos, empalmes, soldadura de tubos, etc., $\mathrm{y}$, en condiciones adecuadas, piezas de hierro.

La adherencia del estaño sobre el material a soldar no es posible sin el empleo de un fundente - desoxidante. El desoxidante para la soldadura de cobre, latón, bronce y hojalata puede ser la resina común o pasta que tiene como base a ésta. Para la soldadura de piezas de hierro se emplea como desoxidante el cloruro de cinc.

Las herramientas empleadas para fundir el estaño son los soldadores eléctrico como los que a continuación se muestran: 


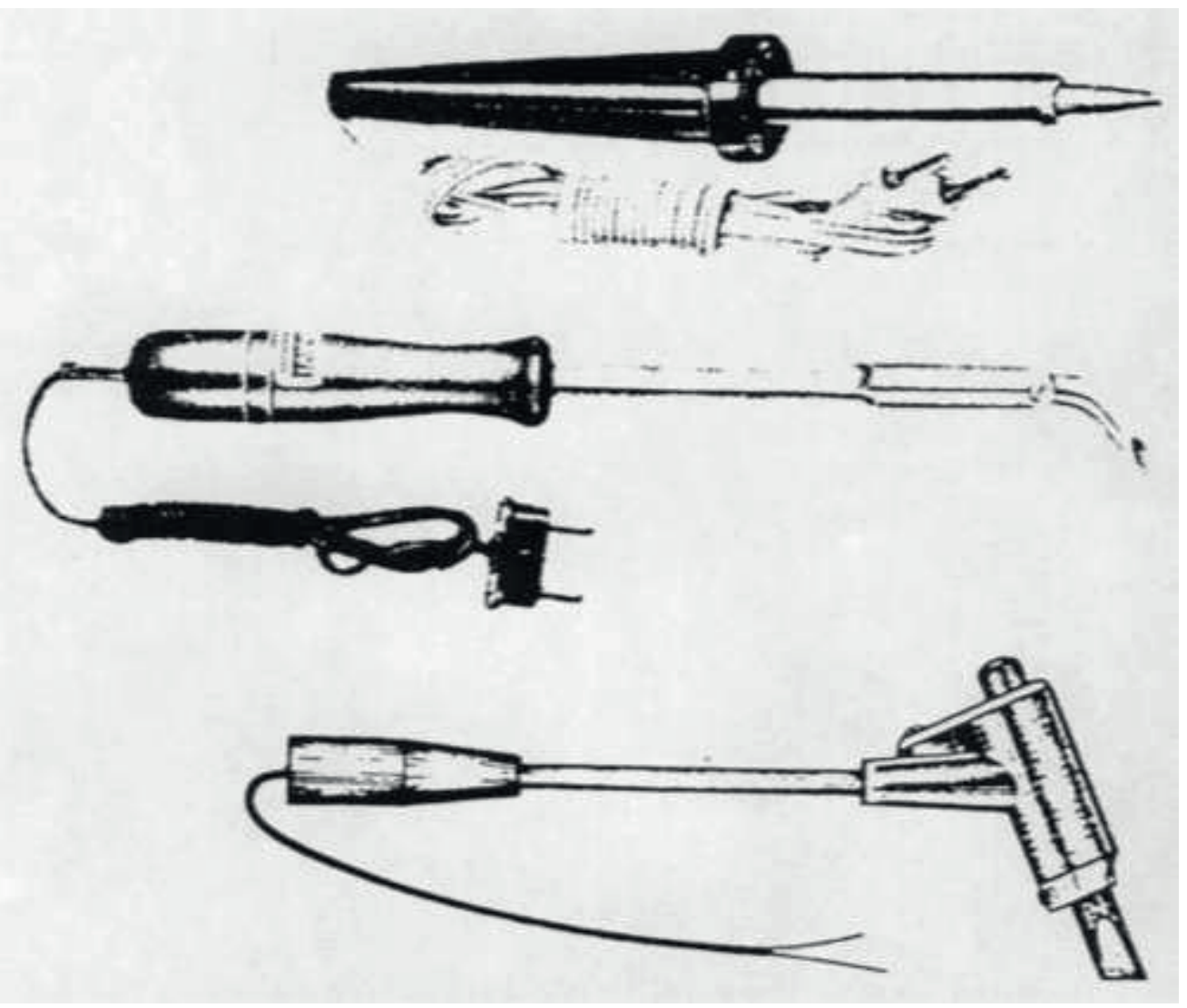

Diversos tipos de soldadores eléctricos

Hay soldadores eléctricos para la soldadura con estaño de varios tipos, como los mostrados, pero todos están basados generalmente en una resistencia alojada en una pieza tubular refractaria. Una punta de cobre, alojada en el hueco de la pieza refractaria, se calienta al conexionar la resistencia a la red, consiguiendo así la temperatura necesaria para la fusión del estaño y realización de la soldadura. La pieza refractaria va alojada en una armadura metálica rematada con un mango de material aislante térmica y eléctricamente. 


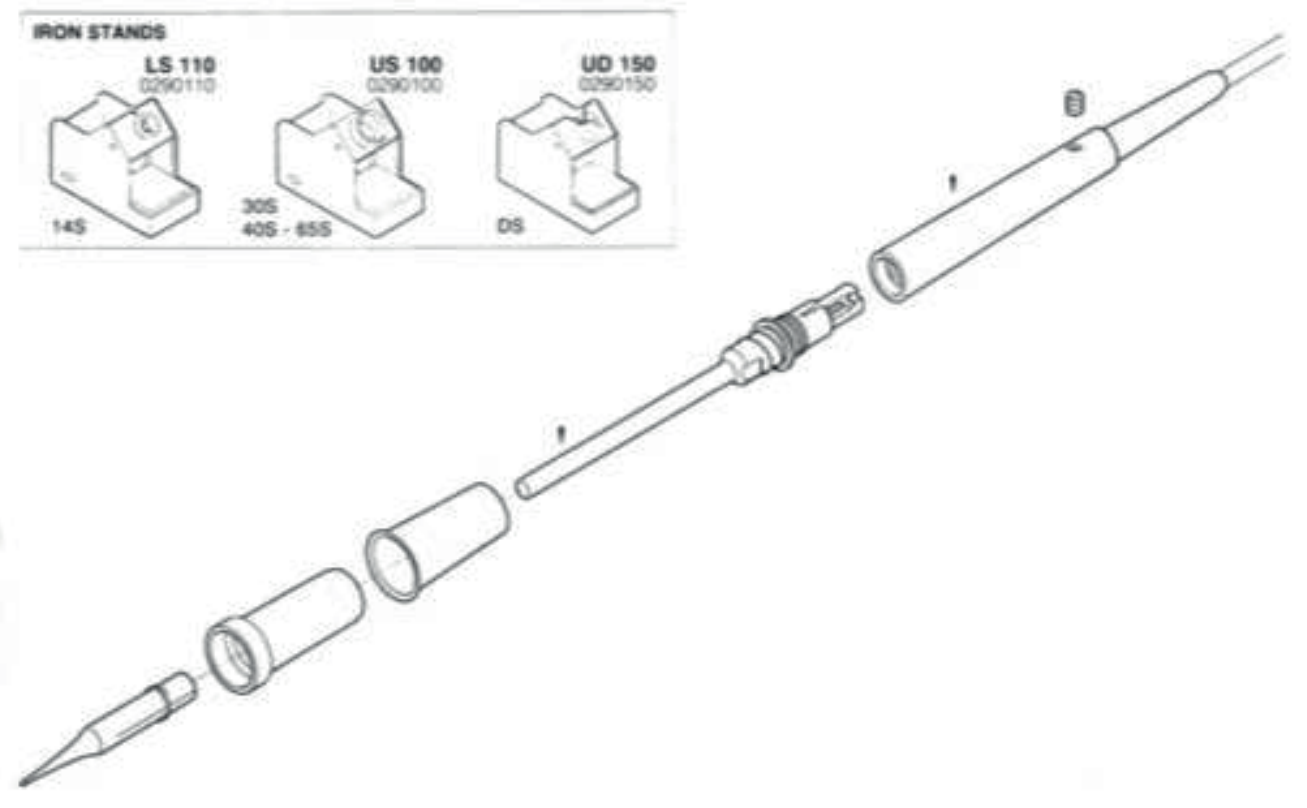

Despiece de un soldador

Otro tipo de soldador es el soldador de caldeo directo o rápido. Este consta de un pequeño transformador con el secundario conexionado a una punta especial que, al ser recorrida por la corriente, se calienta rápidamente produciendo la fusión del estaño y el caldeo de la pieza. Este soldador tiene la forma de pistola, y el encendido se realiza al oprimir un gatillo en la misma herramienta. Este tipo de soldadores y su esquema responde a: 


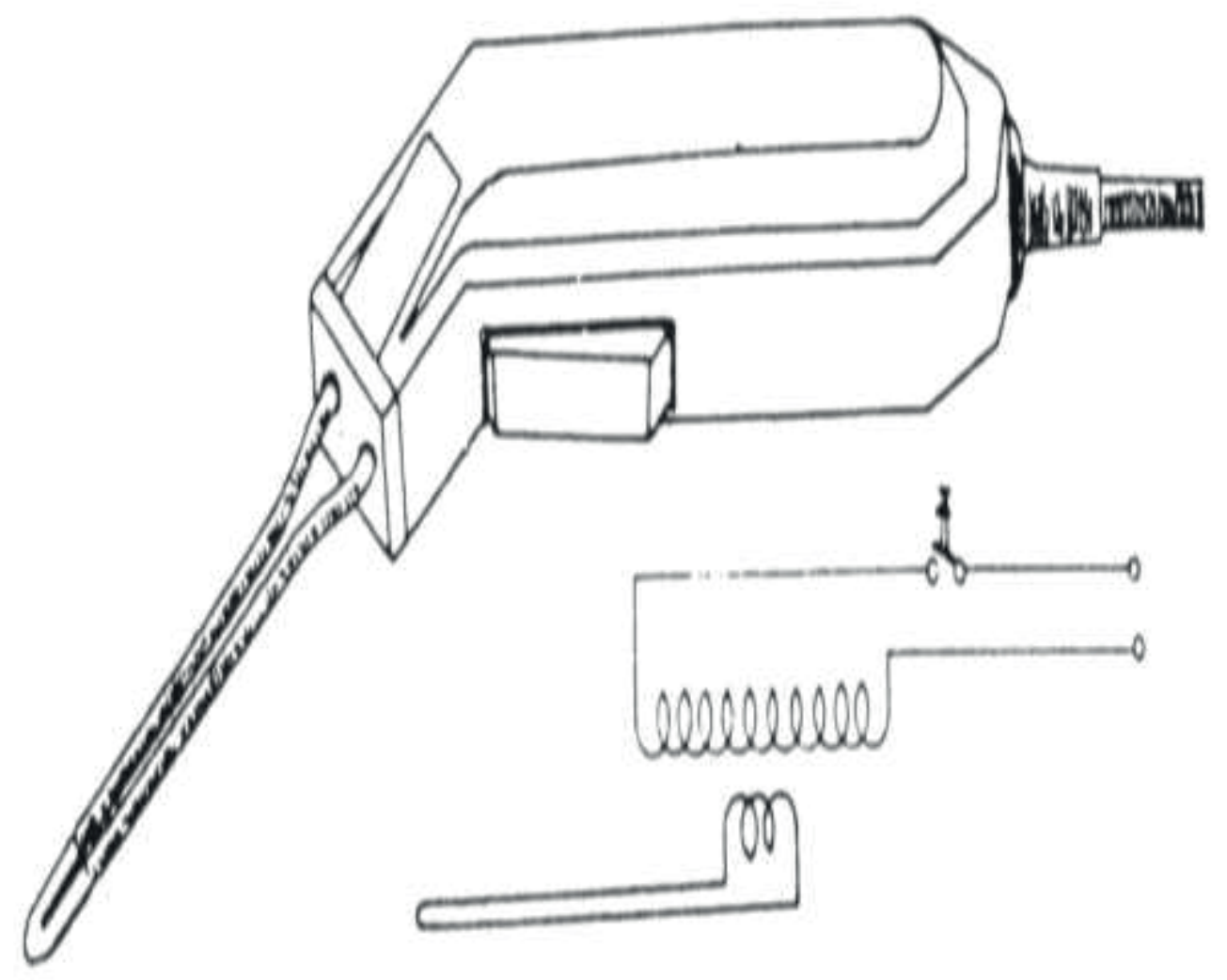

Soldador rápido

La elección del soldador depende de la tarea a realizar, esto resulta obvio. El tamaño y potencia del soldador debe ser adecuado a la pieza que se va a soldar. Tal y como ya se expuso en el primer artículo sobre la soldadura, en la tabla que a continuación expongo, se especifica el tipo de soldador a emplear, según el tipo de trabajo, para aquellos que se la perdieron: 
TABLA: Elección del soldador según el trabajo a realizar

\begin{tabular}{|c|c|c|c|c|}
\hline $\begin{array}{l}\text { Potencia } \\
\text { (watios) }\end{array}$ & $\begin{array}{l}\text { Didmetro } \\
\text { de to punte } \\
\text { (mm) }\end{array}$ & $\begin{array}{c}\text { Temperatura } \\
(\circ \mathrm{C})\end{array}$ & $\begin{array}{l}\text { Tiempo de } \\
\text { calentamiento } \\
\text { (minutos) }\end{array}$ & Utilizacidn \\
\hline 30.40 & 4 & 500 & 3 & $\begin{array}{l}\text { Soldadura en circuitos electricos. } \\
\text { radio y TV con conductores de } \\
\text { seceión inferior a } 0,5 \mathrm{~mm}^{2} \text {. }\end{array}$ \\
\hline 60 & 5,5 & 500 & 4 & $\begin{array}{l}\text { Soldadura en circuitos eléctri- } \\
\text { cos, radio y TV con conducto- } \\
\text { res de sección superior a } 0.5 \mathrm{~mm}^{2} \\
\text { y bases metalicas de espesor } \\
\text { menor a los } 0.2 \mathrm{~mm}^{2} \text {. }\end{array}$ \\
\hline 80 & 8 & 500 & 4 & $\begin{array}{l}\text { Soldadura y conexionado de con- } \\
\text { ductores entre si y sobre bases } \\
\text { metblicas con espesor hasta } 0.3 \\
\text { milimetros. }\end{array}$ \\
\hline $100-120$ & 10 & 500 & 5 & $\begin{array}{l}\text { Soldadura de conductores entre } \\
\text { si con componentes y sobre } \\
\text { chasis. }\end{array}$ \\
\hline 150 & 14 & 500 & 5 & $\begin{array}{l}\text { Soldadura sobre chasis o IAmi- } \\
\text { nas metalicas de hasta } 0.8 \mathrm{~mm} \\
\text { de espesor, empaimes y bahado } \\
\text { de conductores, conexión en pe- } \\
\text { quehos colectores de motores } \\
\text { etcétera. }\end{array}$ \\
\hline 200 & 16 & 500 & 5 & $\begin{array}{l}\text { Soldadura de hilos con seccio- } \\
\text { nes no superiores a los } 6 \mathrm{~mm}^{2} \text {. } \\
\text { piezas merdicas y chapas, ba- } \\
\text { hado de piezas, soldadura de } \\
\text { terminales y colectores, etc. }\end{array}$ \\
\hline
\end{tabular}

Si el soldador es nuevo, se procede al bañado con estaño en la punta de este. Algunos soldadores tienen la punta niquelada, por lo cual se debe comenzar limándola hasta que desaparezca el níquel.

Al bañar la punta, se estará pendiente de la temperatura, comprobando cuándo funde el estaño, momento éste en que se procederá a recubrirla. Esta operación se realiza fundiendo en al punta y por contacto un poco de resina. Posteriormente se aplica estaño que se frota con ayuda de un trapo limpio procurando que éste no sea de nylon o de algún material degradable por calor. 
Conviene hacer notar que estando el soldador muy caliente, se adhiere mal el estaño , por lo cual, como antes hemos indicado, la operación del bañado se debe realizar en el instante en que la temperatura alcanzada empieza a fundir el estaño.

Para aquellos que se perdieron la "receta de cómo soldar" y para recordársela a aquellos que se les olvidó, volveré a exponerla. Estando las piezas limpias y con el soldador preparado, se aplica al punto que se debe soldar para comunicar calor a la pieza. Sin este calor previo la soldadura quedará mal (soldadura fría). Una vez caliente la pieza que se pretende soldar, se aplica un poco de resina o ácido, según el material a soldar, e inmediatamente después el estaño. Con al punta del soldador, al mismo tiempo que se mantiene el calor, se extiende el estaño por todas las partes a soldar.

El soldador no debe alcanzar nunca una temperatura excesiva; por lo que durante el trabajo, cuando se aprecie la fácil fusión del estaño, se desconectará de la red con el fin de mantenerlo a la temperatura adecuada. Hay que mantener siempre la punta del soldador bañada en estaño y a la temperatura ideal.

Para la soldadura en circuitos impresos se requiere una habilidad que se logra con una continua práctica. La soldadura se realiza con una aparente facilidad; pero, de no poner todo el cuidado, fácilmente se realizarán trabajos defectuosos y, en ocasiones, con resultados lamentables.

Para una buena soldadura hay que tener en cuenta las siguientes normas:

El punto a soldar debe estar escrupulosamente limpio.

El punto a soldar, componente o conexión, debe bañarse en estaño para su posterior soldadura. 
Como indicamos anteriormente, para soldaduras generales la temperatura dada a la soldadura es muy importante. Una soldadura fría da como resultado una mala conexión, con los consiguientes trastornos en el circuito. Una temperatura excesiva cambia, por un lado las características del estaño y, por otro deteriora los componentes y aislamientos delicados. De todo esto se deduce claramente la importancia de alcanzar un buen dominio de la soldadura.

El estaño químicamente puro se presenta en el mercado en forma de barras y aleado, en rollos de hilo de diámetros variados. Para utilizar las barras de estaño hay que alearlas convenientemente con plomo, como ya apunté anteriormente. Esta operación se aprovecha para hacer barras de mayor o menor grosor. El estaño en rollos ya está aleado, con mayor o menor cantidad de plomo, y tiene la particularidad de que este hilo, en realidad, es un tubito con el interior relleno de resina como fundente y desoxidante.

\section{DESOLDADURAS}

Hoy día, que se impone el empleo de circuito impreso, es imprescindible disponer de soldadores especiales para desoldar los componentes o partes del circuitos a reponer y, por consiguiente, conseguir el dominio de la desoldadura. Esta se realizará correctamente siguiendo los pasos que a continuación detallo:

Dejar libre de partículas de estaño la superficie del circuito, evitándose cortocircuitos ocasionados por estas partículas

Menor calentamiento en la operación, en beneficio de componentes próximos aislantes y del propio circuito impreso

Dejar los orificios abiertos para la colocación del nuevo componente. El funcionamiento del desoldador, basándonos en la siguiente figura: 


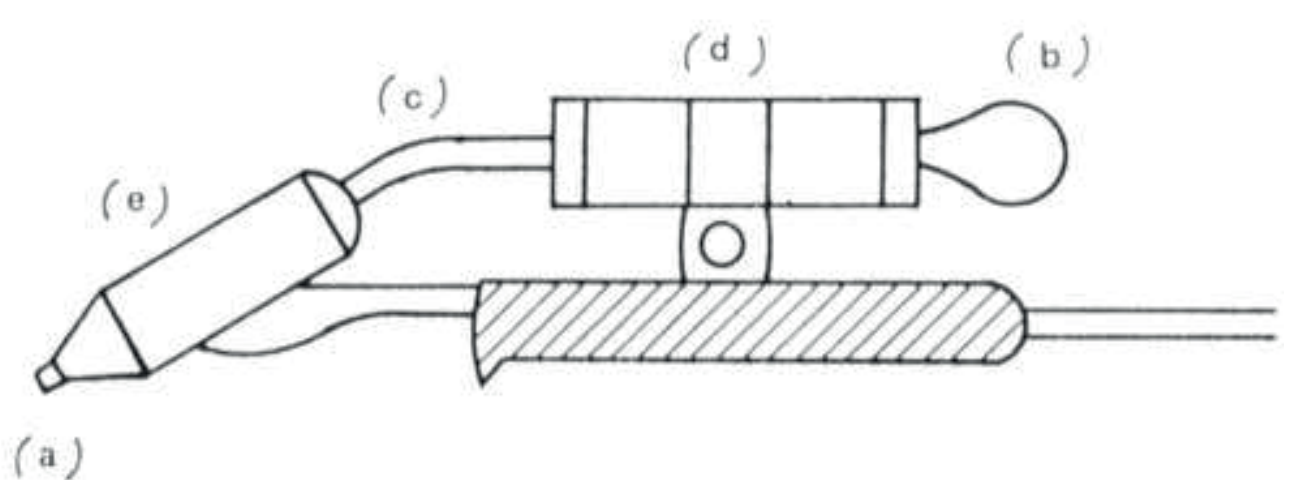

Soldador especial para desoldar

es como sigue: se acopla la punta hueca (a) en el punto a desoldar, se funde el estaño y se aspira mediante el vacío producido por la perilla(b). El estaño aspirado pasa por el tubo (c) hasta el filtro (d), en donde se deposita y puede ser sacado cuando se desee.

A las ventajas indicadas hay que añadir la de poder trabajar con una sola mano y sin precipitaciones, ya que una vez desoldado el componente queda suelto para ser retirado. En algunos casos, según la posición, caerá solo.

Como en los soldadores normales, hay que emplear una punta adecuada según la desoldadura que se vaya a efectuar. En el cuerpo (e) va alojado un elemento calefactor que calienta la punta hueca. En el caso de que el componente sea difícil de sacar por no ser accesibles los puntos de soldadura, se procede a romper el componente (cortando las patillas) dejando los terminales suficientemente largos para soldar en ellos el nuevo componente. 


\section{DS ACCESORY FOR 30S/40S}

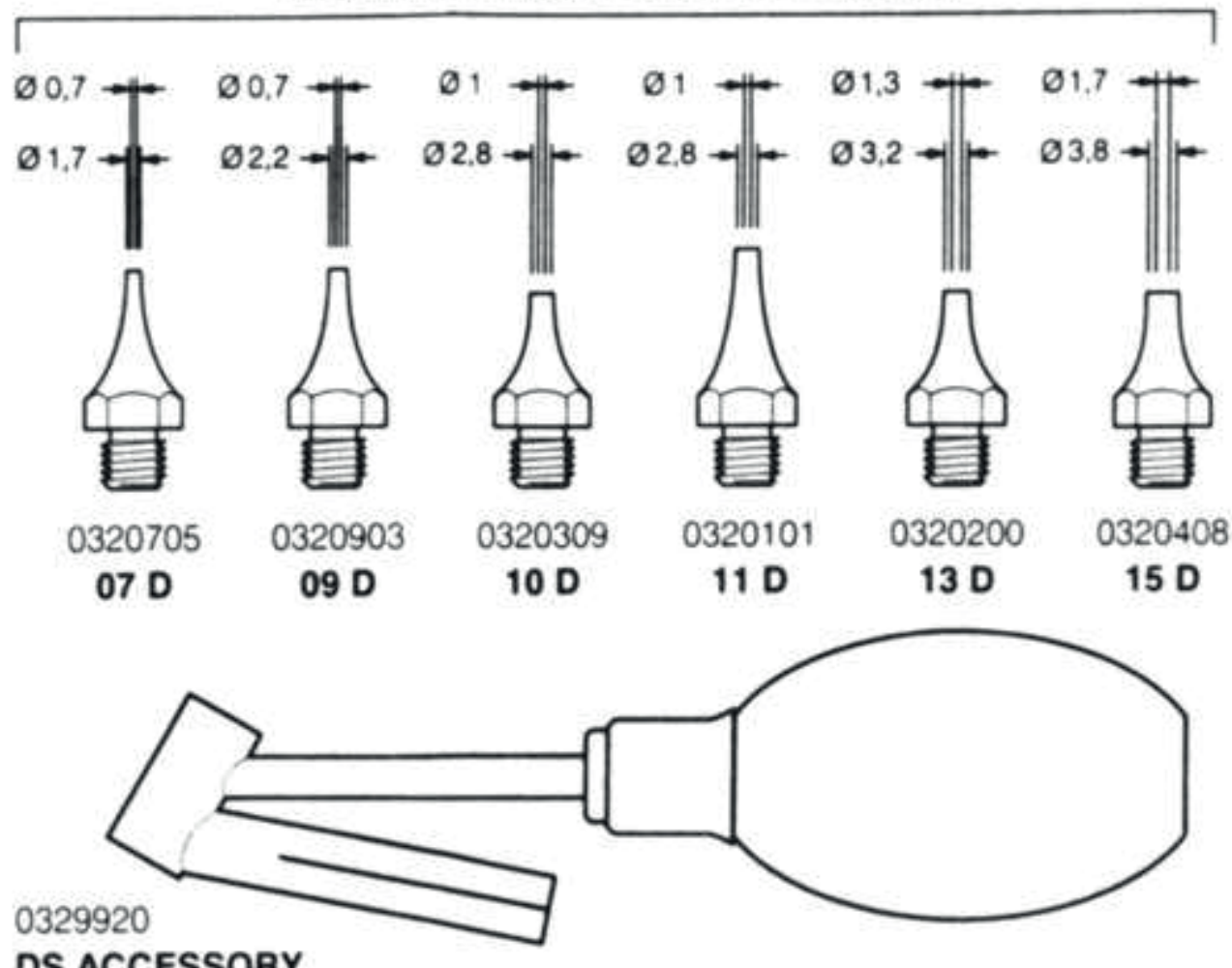

\section{DS ACCESSORY}

Puntas huecas de un desoldador y detalle de la perilla

Otra manera de desoldar es mediante un hilo trenzado que por capilaridad, al licuar el estaño calentándolo, lo absorbe dejando limpio de 'estaño' el punto de conexión entre el terminal del componente y la placa permitiendo así su extracción. Este hilo trenzado viene a ser mas o menos como se muestra a continuación: 

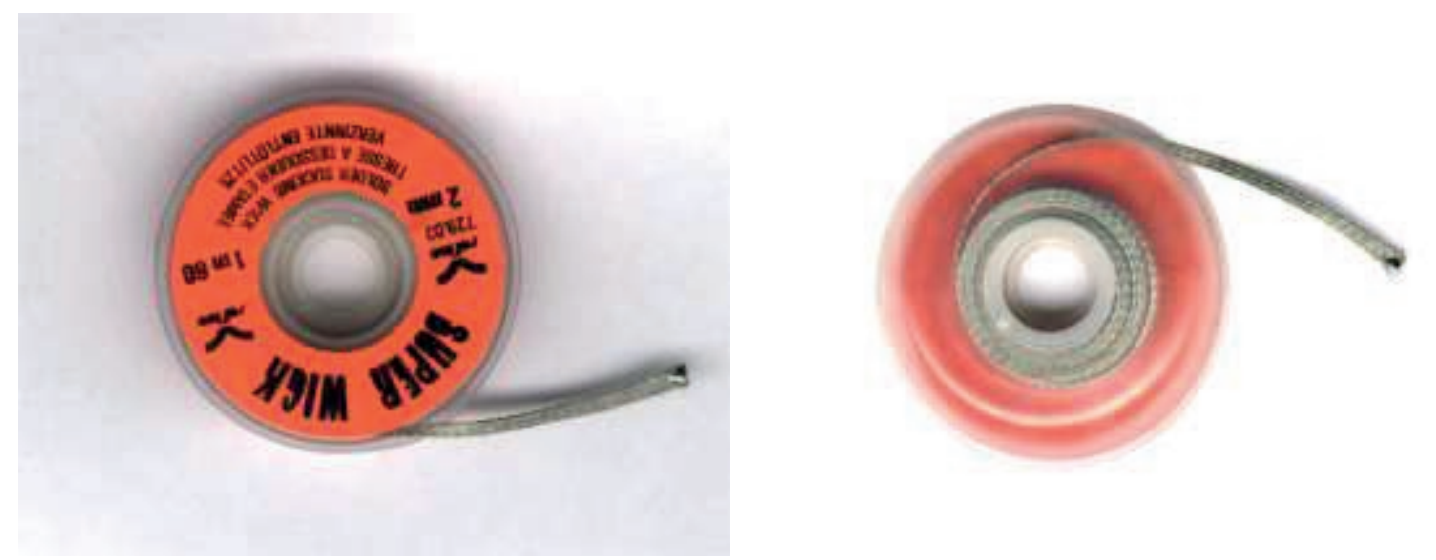

Desoldador de hilo trenzado

Esta manera de desoldar no requiere más herramienta que la del propio soldador y este hilo que, al ir absorbiendo 'estaño', quedará inservible por lo que habrá que recortarlo a medida que se empape.

Pues bien, esto es todo lo que tenía que decir sobre el tema. Por desgracia (o por fortuna, según se mire) mis exiguos conocimientos no llegan más allá. Si alguien pudiera aportar sus conocimientos para expandir éste con nueva información o con el fin de rebatir errores que yo haya cometido en esta exposición, o manifestar críticas (a ser posible constructivas por favor) o cualquier tipo de comentario, les animo a que se dirijan a esta magna revista para que aquí me echen la bronca, esto quiero decir, me lo hagan saber (y hago aquí la solemne promesa: que en cuanto sepa manejar este diabólico artefacto de los "internés de la güeb", publicaré, si ello fuere menester claro, aquello que se me enviare).

Espero que haya resultado del gusto del lector el presente articulo (aunque éste parezca más un "refrito de Agosto" que algo nuevo); si no fue así, desde aquí hago propósito de enmienda para que el próximo salga mejor (eso si no me echan antes por "rollista" ). Si por el contrario le gustó, y despidiéndome una vez más al más puro 
estilo Shakesperiano (tal y como me he marcado en esta revista), quedemos como amigos y volvamos a encontrarnos donde a la diosa fortuna más le complazca. 